\title{
Hepatitis autoinmune precedida por infección aguda por citomegalovirus en una mujer inmunocompetente
}

\author{
Autoimmune hepatitis preceded by acute cytomegalovirus infection \\ in an inmunocompetent woman
}

\author{
María Vares González, Lucía Ramos Merino, Mar Martínez Quintanilla, Ramón Freire Martínez \\ Servicio de Medicina Interna. Complejo Hospitalario Universitario de A Coruña (CHUAC). SERGAS. A Coruña
}

\section{Introducción}

El diagnóstico diferencial de las hepatitis es amplio y complejo, y con mucha frecuencia corresponde al médico internista filiar la etiología de la misma. De etiopatogenia no claramente establecida, lo que caracteriza a la hepatitis autoinmune (HAl) es la pérdida de tolerancia inmune frente a los antígenos de los hepatocitos, conduciendo a la destrucción del parénquima hepático por linfocitos T autorreactivos. El papel de ciertos virus como factores favorecedores de la disregulación autoinmune ha sido propuesto previamente, en base a lo demostrado por los estudios de investigación y a la evidencia clínica. A continuación se expone un caso de HAl precedido por una infección aguda por CMV, lo que otorga al caso un interés particular, pues su incidencia es excepcional, existiendo sólo tres casos recogidos en la literatura (dos de ellos en pacientes sanos de 17 años ${ }^{1,2}$, y otro en un varón inmunodeprimido trasplantado de médula ósea ${ }^{3}$.

\section{Caso clínico}

Mujer de 62 años sin antecedentes personales relevantes que tres años antes había consultado en un médico privado por astenia y síndrome febril siendo diagnosticada de infección aguda por citomegalovirus (CMV). Recibió tratamiento sintomático. En relación con ese episodio aportaba las siguientes pruebas complementarias: AST 705 UI/L (valores normales (VN) 5-40 UI/L), ALT 993 UI/L (VN 5-45 UI/L), GGT 163 UI/L (VN 8-61), FA 316 UI/L (VN 91-258 UI/L), IgM CMV + (10.77), IgG CMV + (6.7), PCR CMV (+), AMA y anti-LKM negativos, SMA 1/20 (título no significativo), ecografía compatible con hepatomegalia. Desde entonces había presentado dos episodios de malestar y coluria que se habían resuelto espontáneamente asociando epístaxis frecuente y sensación de astenia progresiva. Consulta en esta ocasión por epístaxis persistente de 48 horas de evolución. Las constantes vitales eran las siguientes: TA 120/80 mmHg, FC 90 lpm, $T^{a} 36.2^{\circ} \mathrm{C}$, eupneica. En la exploración física destacaba discreta palidez cutáneo-mucosa. Analíticamente: Hb 12 g/dL (VN 11.5-14.5 g/dL), VCM 97.9 fL (VN 80-99 fL), plaquetas $155 \times 109 / \mathrm{L}$ (VN 130-450 x 109/L), leucocitos 6.4 × 109/L (VN 4.510.5 x109/L), TP (COC) 1.4, AST 213 UI/L, ALT 222 UI/L, GGT 81 UI/L, FA 289 UI/L, Br 1.64 mg/dl (VN 0.1-1.3 mg/dL). La radiografía de tórax y el electrocardiograma no mostraron alteraciones. Se realizó cauterización a nivel del plexo de Kiesselbach que resultó exitosa. Dada la presencia de alteraciones analíticas sugestivas de daño hepatocelular, y habiéndose descartado el consumo de tóxicos, fármacos o productos de herboristería se realizó un estudio protocolario destacando los siguientes hallazgos: IgM CMV + (5.6), IgG CMV+ (10.2), PCR CMV (-), SMA + (1/80), LKM + (1/60), lgG 4260 (VN 751-1560 mg/dL), FR $286 \mathrm{Ul} / \mathrm{mL}(\mathrm{VN}<20 \mathrm{Ul} / \mathrm{ml})$, alfaglobulina $3.28(\mathrm{VN}<1.34 \mathrm{~g} / \mathrm{dL})$. El resto de serologías de virus hepatotropos (VHA, VHB, VHC, VEB) fueron negativas. La aldolasa, la CPK y la TSH estaban dentro de la normalidad. El estudio de despistaje de hemocromatosis fue normal. La ecografía abdominal mostró un hígado muy atrófico, de estructura heterogénea y con áreas de fibrosis compatible con cirrosis. La paciente rechazó la realización de biopsia hepática. Pese a ello, según los criterios diagnósticos cuantificados mediante el "Score del Grupo Internacional de Hepatitis Autoinmune" (ver tabla $1^{4}$ ) nuestra paciente sumaba un total de 16 puntos lo que corresponde con el diagnóstico definitivo de $\mathrm{HAl}^{5}$. Se inició tratamiento con prednisona a dosis de $30 \mathrm{mg} /$ día durante 2 semanas, con disminución posterior a 10 mg/día. Un mes después del inicio del tratamiento, la FA y la Br se habían normalizado y la AST y ALT se encontraban discretamente por encima del límite superior de la normalidad. Clínicamente la paciente refería mejoría sintomática, sin sensación de astenia ni nuevos episodios de epistaxis.

\section{Discusión}

La hepatitis autoimune (HAl) es un proceso de inflamación crónica a nivel hepático caracterizado por la presencia de hipergammaglobulinemia, autoanticuerpos y el hallazgo de necrosis erosiva periportal y centrolobulillar en el estudio histopatológico ${ }^{6}$.

La hipótesis etiopatogénica más aceptada defiende que en personas con una susceptibilidad genética determinada (HLA -DR3/DR4/B8, mutaciones en el gen AIRE...) y/o fallos en los mecanismos de inmunotolerancia (mutaciones en los linfocitos T reguladores-citotóxicos/células B) actuaría un desencadenante ambiental (virus, fármacos, tóxicos...), condicionando la pérdida de tolerancia frente a los autoantígenos hepáticos. En relación con el papel viral, la teoría más plausible es la del mimetismo molecular, según la cual 
algunos antígenos víricos que presentan cierta homología con los autoantígenos producirían una reacción humoral cruzada, iniciando la producción de autoanticuerpos que conduce al daño tisular. A su vez, el ambiente proinflamatorio generado por el virus (mediado por la liberación de citoquinas), activaría a las células T autorreactivas, modificando el procesamiento y presentación de autoantígenos, jugando un papel crítico a la hora de perpetuar la generación de autoanticuerpos ${ }^{7,8}$. Los virus que con mayor frecuencia desencadenan HAl corresponden a la familia de los herpesvirus y son el VHA ${ }^{9}$, seguido del VHB y el VHC. Con menos frecuencia han sido descritos en relación con infección por el VEB, el CMV, el VH-6 y el sarampión. En el caso concreto de nuestra paciente cabe destacar que la lgM positiva para CMV detectada se trata de un falso positivo, que podría estar justificado tanto por la presencia de un factor reumatoide extremadamente elevado, como por la producción humoral descontrolada en el contexto de la hipergammaglobulinemia policlonal que presentan estos enfermos. La posibilidad de determinar la carga viral del CMV mediante la PCR (reacción en cadena de la polimerasa) facilita la interpretación de la lgM del CMV. La HAl predomina en mujeres (7 veces más frecuente) y clínicamente puede manifestarse de forma fulminante 0 indolente, aunque lo habitual es un curso fluctuante. Como proceso autoinmune que es se encuentra asociada a otras enfermedades con esta misma patogenia. Las HAl se clasifican en función de los marcadores serológicos existentes en HAl tipo 1 (constituye el 80\% de los casos y presenta autoanticuerpos ANA y/o SMA y/o SLA -posible factor de mal pronóstico-) y la tipo 2 (anticuerpos Anti LKM1-3 y/o LC1), aunque en muchas ocasiones existe autoinmunidad cruzada. Las indicaciones de tratamiento se encuentran recogidas en la tabla $2^{10}$. Los pilares terapéuticos son los inmunosupresores, fundamentalmente los córticoesteroides y la azatioprina.
Tabla 1. Criterios diagnósticos de HAl Score del Grupo Internacional de Hai

\begin{tabular}{|c|c|c|}
\hline Sexo & Mujer & +2 \\
\hline FA/AST (o ALT) & $\begin{array}{c}>3 \\
<1.5\end{array}$ & $\begin{array}{l}-2 \\
+2\end{array}$ \\
\hline $\begin{array}{l}\text { aglogulina o IgG por encima } \\
\text { de lo normal }\end{array}$ & $\begin{array}{c}>2 \\
1.5-2 \\
1.0-1.5 \\
<1\end{array}$ & $\begin{array}{c}+3 \\
+2 \\
+1 \\
0\end{array}$ \\
\hline $\begin{array}{l}\text { Titulos de ANA, SMA o anti } \\
\text { LKM1 }\end{array}$ & $\begin{array}{c}>1 / 80 \\
1 / 80 \\
1 / 40 \\
<1 / 40\end{array}$ & $\begin{array}{c}+3 \\
+2 \\
+1 \\
0\end{array}$ \\
\hline AMA & + & -4 \\
\hline Marcadores virales & $\begin{array}{l}+ \\
-\end{array}$ & $\begin{array}{r}-3 \\
+3\end{array}$ \\
\hline Drogas & $\begin{array}{l}\text { Sí } \\
\text { No }\end{array}$ & $\begin{array}{c}4 \\
+1 \\
+1\end{array}$ \\
\hline Alcohol & $\begin{array}{l}<25 \mathrm{~g} / \mathrm{día} \\
>60 \mathrm{~g} / \mathrm{dia}\end{array}$ & $\begin{array}{l}+2 \\
-2\end{array}$ \\
\hline HLA & DR3 o DR4 & +1 \\
\hline Enfermedad inmune & Tiroiditis, colitis & +2 \\
\hline Otros marcadores & $\begin{array}{c}\text { Anti SLA, anti-actina, anti } \\
\text { LC1, pANCA }\end{array}$ & +2 \\
\hline Datos histológicos & $\begin{array}{l}\text { Hepatitis de interfase } \\
\text { Plasmocitos } \\
\text { Rosetas } \\
\text { Ninguno de los previos } \\
\text { Cambios biliares } \\
\text { Otros cambios }\end{array}$ & $\begin{array}{l}+3 \\
+1 \\
+1 \\
-5 \\
-3 \\
-3\end{array}$ \\
\hline Respuesta al tratamiento & $\begin{array}{l}\text { Completa } \\
\text { Recaída }\end{array}$ & $\begin{array}{l}+2 \\
+3\end{array}$ \\
\hline
\end{tabular}

PUNTUACIÓN PRE- TRATAMIENTO

Dxco. Definitivo: > 15 / Dxco. Probable: 10-15 PUNTUACIÓN POS-TRATAMIENTO

Dxco. Definitivo: > 17 / Dxco. Probable: 12-17

AMA, anticuerpos antimitocondriales; anti LC1, anticuerpos contra citosol hepático tipo 1; anti LKM1, anticuerpos contra microsomas hepáticos/renales tipo 1; anti SLA, anticuerpos contra el antígeno soluble hepático; ANA, anticuerpos antinucleares; FA:AST (o ALT) cociente, cociente entre la fosfatasa alcalina y la aspartato o alanina aminotrasferasa; HLA, antígeno leucocitario humano; pANCA, anticuerpos anticitoplasma de neutrófilo, patrón perinuclear; SMA, anticuerpos antimúsculo liso.

Tabla 2. Indicaciones de tratamiento

\begin{tabular}{|c|c|c|}
\hline INDICACIONES ABSOLUTAS (IA) & INDICACIONES RELATIVAS (IC) & CONTRAINDICACIONES \\
\hline$A S T \geq 10$ veces $L S N$ & Síntomas (fatiga, artralgias, picor...) & Asintomático con AST y gammaglobulina casi normales \\
\hline $\begin{array}{l}\text { AST } \geq 5 \text { veces } L S N \text { y } \\
\text { gammaglobulina } \geq 2 \text { veces } L S N\end{array}$ & $\begin{array}{l}\text { AST y/o gammaglobulina menor que los criterios } \\
\text { absolutos }\end{array}$ & Cirrosis inactiva o hepatitis portal \\
\hline $\begin{array}{l}\text { AP: Necrosis multiacinar o en } \\
\text { puentes }\end{array}$ & Hepatitis de interfase & $\begin{array}{l}\text { Citopenia severa ( leucocitos }<2.5 \times 109 / \mathrm{L} 0 \\
\text { plaquetas }<50 \times 109 / \mathrm{L} \text { ) } 0 \text { ausencia de actividad de la TPMT } \\
\text { contraindica el uso de Azatioprina. }\end{array}$ \\
\hline Síntomas incapacitantes & $\begin{array}{l}\text { Osteopenia, inestabilidad emocional, HTA, DM } 0 \\
\text { citopenia ( leucocitos } \leq 2.5 \times 109 / \text { L o plaquetas } \leq \\
\text { 50X109/L) }\end{array}$ & $\begin{array}{l}\text { Compresión vertebral, psicosis, diabetes o HTA mal } \\
\text { controladas, intolerancia conocida a la prednisona o a la } \\
\text { azatioprina. }\end{array}$ \\
\hline
\end{tabular}


En casos de presentación aguda refractarios a tratamiento corticoideo durante dos semanas podría considerarse el trasplante hepático. En los pacientes mayores de 60 años, edad en la que debutan un $20 \%$ de las HAl, la respuesta a los corticoides suele ser buena (aunque deben utilizarse dosis menores, durante menos tiempo y prevenir la osteopenia), pero no existe experiencia suficiente que permita recomendar el uso de la azatioprina ${ }^{11}$. El seguimiento debe realizarse mediante ecografía y alfa-feto cada 6-12 meses (evidencia C), siendo controvertida la necesidad de realizar biopsia hepática de control a los 2 años del diagnóstico. El objetivo fundamental del tratamiento es la resolución de los síntomas y la normalización de la Br y la FA. Los autoanticuerpos no tienen papel en la monitorización. La presencia de cirrosis es el principal factor de mal pronóstico ${ }^{12}$.

\section{Bibliografía}

1. Mouelhi L, Debbeche R, Salem M, Bouzaidi S, Mekki H, Houissa F, Said Y et col. Autoimmune hepatitis type 1 triggered by cytomegalovirus infection. One case report. Tunis Med. 2010; 88 (9): 674-7.

2. Castellote J, Güell E, Porta F. Autoimmune hepatitis following citomegalovirus infection. Med Clin (Barc). 2001; 117 (2): 76

3. Kamisato T, Tsubaki K, Adachi Y. Autoimmune hepatitis after cytomegalovirus infection in a bone marrow-trasplanted patient. Am J Gastroenterol 1997; 92: 1238-1239.

4. Álvarez F, Berg PA, Bianchi FB, Bianchi L, Burroughs AK, Cancado EL et al. International Autoimmune Hepatitis Group Report: review of criteria for diagnosis of autoimmune hepatitis.J. Hepatol 1999; 31: 929-938.

5. Czaja AJ. Comparability of probable and definite autoimmune hepatitis by international diagnostic scoring criteria. Gastroenterology. 2011; 140 (5): 1472-80.

6. Autoimmune Hepatitis. Edward L, Krawitt EL. N Engl J Med. 2006; 354 (1): 54-66.

7. Oo YH, Hubscher SG, Adams DH. Autoimmune hepatitis: new paradigms in the pathogenesis, diagnosis, and management. Hepatol Int. 2010; 4 (2): 475-93.

8. Vogel A, Manns MP, Strassburg CP. Autoimmunity and viruses. Clin Liver Dis. 2002; 6 (3): 739-53.

9. Del Pozo D, Cano A, Peña E, Miquel J, Valer M, Alemán S, Merino J. Autoimmune hepatitis with prolonged IgM antibodies to HAV. Are serological markers reliable in ruling out a diagnosis of autoimmune hepatitis? Gastroenterol Hepatol. 2001; 24 (8): 387-9.

10. Manns MP, Czaja AJ, Gorham JD, Krawitt EL, Mieli-Vergani G, Vergani D, Vierling JM; American Association for the Study of Liver Diseases. Diagnosis and management of autoimmune hepatitis. Hepatology. 2010; 51(6): 2193-213.

11. Czaja AJ. Clinical features, differential diagnosis and treatment of autoimmune hepatitis in the elderly. Drugs Aging. 2008; 25 (3): 219-39.

12. Feld JJ, Dinh H, Arenovich T, Marcus VA, Wanless IR, Heathcote EJ. Autoimmune hepatitis: effect of symptoms and cirrosis on natural history and outcome. Hepatology. 2005; 42( 1): 53-62 